\title{
Effect of surfactant therapy using an orogastric tube for tracheal catheterization in preterm newborns with respiratory distress
}

\author{
Tomar RPS ${ }^{1}$, Ghuliani $\mathbf{R}^{2}$, Yadav $\mathbf{D}^{3}$ \\ ${ }^{1}$ Dr RPS Tomar, ${ }^{2}$ Dr R Ghuliani, ${ }^{3}$ Dr D Yadav, all authors are affiliated with Department of Pediatrics, Base Hospital \& \\ Army College of Medical Sciences, Delhi Cantt, India.
}

Address for Correspondence: Dr RPS Tomar, Email: tomar15@rediffmail.com

\begin{abstract}
Introduction: Respiratory distress syndrome (RDS) due to surfactant deficiency requires surfactant therapy for which InSurE method (Intubate, Surfactant, Extubate) has been widely used. However this method requires intubation and positive pressure ventilation, even for a short time which is enough to initiate significant lung injury. Recently, surfactant administration by Minimally Invasive Surfactant Therapy (MIST) using a fine catheter under direct laryngoscopy in spontaneously breathing preterms while on nCPAP has reported good outcomes. We prospectively assessed the outcome of a modified MIST method of surfactant administration using an orogastric tube in preterms with RDS. Materials \& Methods: A single centre, prospective observational study was conducted where all consecutive eligible inborn preterm neonates with gestation age more than 24 weeks but less than 34 weeks and suffering from RDS were enrolled to receive surfactant using MIST. Results were compared with a historical cohort of preterm who received surfactant with INSURE techniques. Results: Sixty four cases in the modified MIST group were compared with a historic cohort of 68 cases in INSURE group. There were no differences in the requirement of intubation and mechanical ventilation in the first 72 hours but the duration of MV and CPAP were significantly less in modified MIST group. Other neonatal morbidities and mortality rates were similar in either of the groups. Conclusion: The modified MIST technique is an effective method for the treatment of RDS in preterms with better clinical efficacy and comparable outcomes than the more invasive INSURE procedure and deserves further evaluation.
\end{abstract}

Key words: InSurE, Surfactant, Preterm, Minimal Invasive Surfactant Therapy, Respiratory Distress

\section{Introduction}

During the last three decades there were significant advances in neonatology to improve the overall survival of the preterms neonates. Among these interventions, the significant ones have been antenatal steroids, surfactant therapy and gentler modes of ventilation since the commonest and earliest cause of mortality and morbidity in preterms has been respiratory distress syndrome (RDS) due to surfactant deficiency [1, 2]. However this drastic fall in mortality was not associated with an overall decrease in the long term morbidity due to bronchopulmonary dysplasia (BPD) [3].

Manuscript received: $11^{\text {th }}$ September 2016

Reviewed: $24^{\text {th }}$ September 2016

Author Corrected; $9^{\text {th }}$ October 2016

Accepted for Publication: $22^{\text {nd }}$ October 2016
After a meta-analysis of trials indicated that early nCPAP combined with beneficial effects of surfactant significantly reduced the need for ventilation and subsequent BPD, a combination of these methods called as Intubate, Surfactant, Extubate (InSurE) method was propagated which has since been widely used [4]. However this method also requires intubation for surfactant administration and positive pressure ventilation, even for a short time which is enough to initiate significant lung injury as it was observed that even these few large artificial breaths increased the risk of BPD [5]. Researchers have thus been looking for less invasive ways to administer surfactant without the need for intubation in an effort to reduce BPD. Recently there were reports of surfactant administration into 
trachea by Minimally Invasive Surfactant Therapy (MIST) using a fine catheter under direct laryngoscopy in spontaneously breathing preterms and while on nCPAP which lead to an even better dispersion of surfactant throughout the lungs along with better tolerance and decreased requirement for subsequent mechanical ventilation (MV) [6].

Observing the convenience and benefits of this method over INSURE, our unit started using a modified method of original MIST method where we did not use any forceps during the procedure for tracheal catherization for surfactant installation.

In this study we prospectively assessed the outcome of this method of surfactant administration using modified MIST in preterm newborns less than 34 weeks of gestation with RDS requiring surfactant and compared it with our earlier cohort of preterms who had received surfactant with INSURE technique.

\section{Methodology}

This was a single centre, prospective observational study which was conducted in a teaching hospital of Delhi. Institutional ethics approval and parental consent were obtained. All consecutive inborn preterm neonates with gestation age more 24 weeks but less than 34 weeks and suffering from RDS due to surfactant deficiency were eligible for the study.

All preterms were first stabilized in labour room and then shifted to NICU. In a few cases, T-piece device (Baby puff 1020, Infant Resuscitator; Fenem Inc) was only used to deliver positive end expiratory pressure (PEEP) at 5 to $7 \mathrm{~cm}-\mathrm{H} 2 \mathrm{O}$. Infants were not included in the study if they were resuscitated with intubation at delivery, had major congenital malformations or nasopharyngeal anomaly.

RDS was diagnosed if the patient had grunting, tachypnea, chest recessions, requiring supplemental oxygen to maintain saturations with a typical $\mathrm{x}$-ray findings. Blood gases were done in all cases. Such patients were put on nCPAP and criteria for surfactant treatment was if they continued to have RDS with a need for supplement inspired oxygen with Fio2 $>0.4$ to maintain oxygen saturation $(\mathrm{SpO} 2)$ above $85 \%$ to $92 \%$ in the first two hour of life.
Modified MIST Procedure- All enrolled preterms in the procedure were continued on bubble nCPAP system (BC 151 with MR850 humidifier, Fisher and Pykel Healthcare Inc) at PEEP with 5 to $7 \mathrm{~cm} \mathrm{H}_{2} \mathrm{O}$ which was delivered by positioning Hudson binasal prongs as interface. Once the patient was stabilized, a sterile orogastric tube (5 Fr, Lifeline, India) was inserted through the vocal cords through desired length from the vocal cords uder direct visualization using standard direct laryngosopy with Miller 00 blades. After insertion the laryngoscope was removed and the nasogastric tube was manually held in place. A prewarmed surfactant (Survanta) at a dose of $100 \mathrm{mg} / \mathrm{kg}$ $(4 \mathrm{ml} / \mathrm{kg})$ was then administered in $30-45$ seconds and the orogastric tube was then at once withdrawn. CPAP support was continued throughout the procedure. During the procedure the preterms were monitored continuously and procedure was withheld if they suffered apnea, bradycardia (< 100/min) or desaturation $(<80 \%)$. This group of patients (MIST) were then compared with a historical group of preterms who had received surfactant with INSURE technique which was the unit policy till then.

INSURE Procedure-The patients who received surfactant using INSURE technique were initially intubated with endotracheal tube followed by surfactant installation at a dose of $100 \mathrm{mg} / \mathrm{kg}(4 \mathrm{ml} / \mathrm{kg})$ while performing manual lung inflation using a $\mathrm{T}$-piece device. The patient then was promptly extubated on to nCPAP support, similar to the MIST procedure. The inclusion and exclusion criteria were similar in both procedures.

No sedation or atropine was used in either of both the groups. The subsequent management after either the MIST or INSURE procedure was as per the unit guidelines. Silverman Anderson score (SAS) [7] along with other routine monitoring was regularly done in all patients. If patient deteriorated after 6 hours with increasing respiratory distress or increasing oxygen requirement then a second dose of surfactant was repeated using the same procedure as done during the first administration. In either of the procedure CPAP was considered to have failed and patient was intubated and ventilated if $\mathrm{FiO}_{2}$ was >0.6, PEEP> $7 \mathrm{~cm} \mathrm{H}_{2} \mathrm{O}$, $\mathrm{pCo}_{2}>65, \mathrm{pH}<7.2$, had recurrent apnoea or increasing work of breathing (deteriorating SAS). Necrotising 
enterocolitis (NEC) was diagnosed according to modified Bell's staging, at stages II or greater [8]. Pulmonary haemorrhage was diagnosed on obtaining blood tinged on tracheal aspirate. Early and late-onset sepsis was defined on the basis of positive sepsis screen and blood cultures before or after first 72 hours of life, respectively. BacT/ALERT 3D (Biomerieux) blood culture bottles were used. International classification of retinopathy was used to classify Retinopathy of prematurity (ROP) [9]. Grading of intraventricular hemorrhage (IVH) was as per the Papile grading system [10]. Bronchopulmonary dysplasia (BPD) was defined according to the National Institutes of Health consensus definition [11].

Statistical Analysis- The main aim of the study was to assess the feasibility of this procedure with primary outcomes being need for mechanical ventilation (MV) within first 72 hours of life. On the basis of incidences from earlier studies where $50 \%$ of the patients required MV within 72 hours of birth and to have a significant decrease in incidence to $30 \%$ (i.e. a decrease by $45 \%$ ) for the need for MV in $<72$ hours of life in the MIST procedure, we estimated a minimum sample size of 60 in each group with an enrolment ratio of 1, alpha error of .05 to yield $>80 \%$ power. Variables on continuous scales were compared using $t$ tests or Mann Whitney $U$ tests, as applicable. While variables on nominal types of data were compared using Chi Square or Fisher Exact tests, as proper. A $p$ value <.05 was considered significant. SPSS software version 17.0 (IBM SPSS Statistics, IBM Corporation, Armonk, NY) was used for performing the statistical evaluation of our data.

\section{Result}

During the INSURE procedure period a total of 131 preterms were eligible for the study out of which 63 were excluded due various reasons and 68 cases were analysed (Fig1). Similarly during the modified MIST procedure period a total of 159 preterms were eligible of which only 64 cases were analysed. The baseline demographic data of each group did not show any difference (Table 1). There was also no difference in the postnatal age and time interval of surfactant administration in both the groups. Immediate respiratory outcomes and relevant morbidities are shown in Table 2 . There were no differences in CPAP failure rates, i.e. the requirement of intubation and mechanical ventilation in the first 72 hours ( $\mathrm{p}>0.0 .40$ ) but the duration of MV (66 hrs in INSURE versus 33 hrs in modified MIST, $\mathrm{p}<0.001)$ and CPAP (126 hrs in INSURE versus $81 \mathrm{hrs}$ in modified MIST, $p<.002)$ were significantly less in modified MIST group. There were no differences in neonatal morbidities such as intraventricular haemorrhage, patent ductus arteriosus or retinopathy of prematurity $(\mathrm{p}>0.05)$. There was a decreasing incidence of NEC in the modified MIST group which was though not statistically significant $(\mathrm{p}<0.13)$. Similarly there were similar BPD and mortality rates in either of the groups.

INSURE group

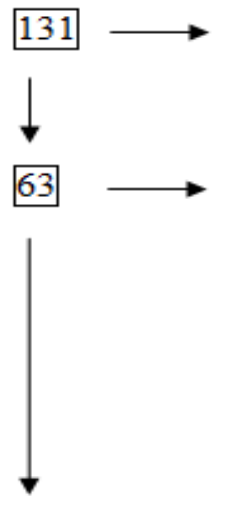

68

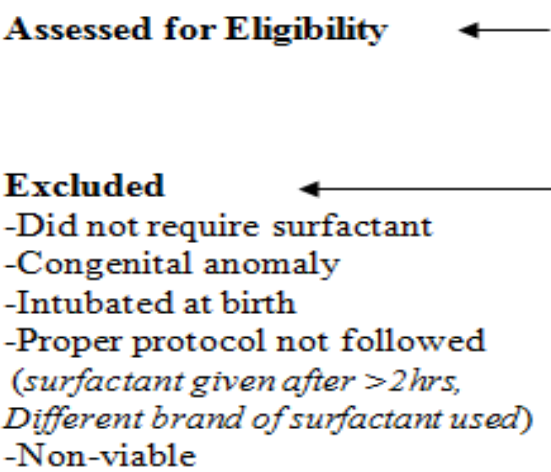

Analysed
Modified MIST group

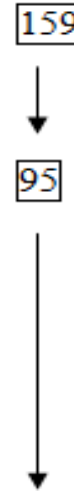

64

Fig-1: Participant chart 
Table-1: Base line demographic data in both groups.

\begin{tabular}{|c|c|c|c|}
\hline & INSURE(n=68) & Modified MIST(n=64) & $\boldsymbol{p}$ \\
\hline Gestational Age (weeks) & $30.6(+2)$ & $30.3(+3)$ & 0.495 \\
\hline Birth weight, gms & $1120(+342)$ & $1085(+414)$ & 0.595 \\
\hline Twin delivery, n(\%) & $12(17.7 \%)$ & $13(20 \%)$ & 0.696 \\
\hline Antenatal Steroids, n (\%) & $44(64.7 \%)$ & $47(73.4 \%)$ & 0.279 \\
\hline Type of delivery, Caesarean, n(\%)- & $45(66.1 \%)$ & $41(64 \%)$ & 0.798 \\
\hline APGAR at 5 min & $7(6-9)$ & $8(6-9)$ & 0.689 \\
\hline Male, n(\%) & $35(51.4 \%)$ & $30(46.8 \%)$ & 0.597 \\
\hline $\begin{array}{c}\text { Time interval from birth to surfactant } \\
\text { administration (min) }\end{array}$ & $54(+38)$ & $46(+24)$ & 0.158 \\
\hline
\end{tabular}

Table-2: Respiratory outcomes and relevant morbidities

\begin{tabular}{|c|c|c|c|}
\hline & INSURE(n=68) & Modified MIST(n=64) & $p$ \\
\hline Second dose of surfactant, $\mathrm{n}(\%)$ & $15(22 \%)$ & $11(17.1 \%)$ & 0.48 \\
\hline CPAP failure, $\mathrm{n}(\%)$ & $18(26.4 \%)$ & $13(20.3 \%)$ & 0.40 \\
\hline Duration of $\mathrm{MV}, \mathrm{h}$ (range), median & $66(28-168)$ & $33(22-144)$ & $<0.001 *$ \\
\hline Duration of CPAP, $\mathrm{h}$ (range), median & $126(72-240)$ & $81(24-176)$ & $<0.002 *$ \\
\hline Pneumothorax, $\mathrm{n}(\%)$ & $3(4.4 \%)$ & $0(0.0 \%)$ & 0.26 \\
\hline Pulmonary interstitial emphysema, n(\%) & $2(2.9 \%)$ & $1(1.5 \%)$ & 0.96 \\
\hline Pulmonary Haemorrhage, $\mathrm{n}(\%)$ & $5(7.3 \%)$ & $3(4.6 \%)$ & 0.78 \\
\hline Patent ductus arteriosus, $\mathrm{n}(\%)$ & $7(10.2 \%)$ & $9(14 \%)$ & 0.51 \\
\hline Necrotising enterocolitis, $\mathrm{n}(\%)$ & $14(20.5 \%)$ & $7(11 \%)$ & 0.13 \\
\hline Retinopathy of prematurity, n(\%) & $4(5.9 \%)$ & $3(4.7 \%)$ & 0.76 \\
\hline Intraventricular haemorrhage, $\mathrm{n}(\%)$ & $6(8.8 \%)$ & $2(3.1 \%)$ & 0.31 \\
\hline Early onset sepsis, (+ve screen) n(\%) & $11(16 \%)$ & $10(15.6 \%)$ & 0.72 \\
\hline Culture proven, $\mathrm{n}(\%)$ & $6(8.8 \%)$ & $7(11 \%)$ & \\
\hline Late onset sepsis, (+ve screen) n(\%) & $26(38.2 \%)$ & $21(32.8 \%)$ & 0.98 \\
\hline Culture proven, $\mathrm{n}(\%)$ & $11(16 \%)$ & $9(14 \%)$ & \\
\hline Brochopulmonary dysplasia, n(\%) & $4(5.8 \%)$ & $1(1.5 \%)$ & 0.49 \\
\hline Mortality, n(\%) & $3(4.4 \%)$ & $2(3.1 \%)$ & 0.94 \\
\hline
\end{tabular}

\section{Discussion}

The results from our study suggest that this modified technique for administering surfactant using orogastric tube and without endotracheal intubation and positive pressure ventilation is well tolerated by preterms on CPAP for treatment of RDS. We found similar efficacy while comparing the primary outcome of need for intubation and then MV after surfactant administration within $72 \mathrm{hrs}$ of birth where 13(20.3\%) required MV in the modified MIST group while $16(23.5 \%)$ required MV in the INSURE group.
However preterms managed with the modified MIST technique had significant shorter duration of either nCPAP or MV than the INSURE technique in our study $(\mathrm{p}<.05)$. Similar results have also been reported by Göpel et al in a multi centric trail [12] and in Kribs study [13]. While Kanzmaz et al called it Take-Care technique and found significant reduction even in intubation and MV rates in their Take-Care group compared to the INSURE group [14]. This variation with our results could be due to their more use of $2^{\text {nd }}$ 
dose of surfactant (in more than $21 \%$ cases in their MIST group vs $17 \%$ in our MIST study). Aguar et al also reported more use of repeat dose of surfactant $(36 \%)$ in their MIST group but they used a much lower surfactant's recommended dose [15]. Again similar to these studies we observed no difference in incidence of NEC, intracranial or pulmonary haemorrhage or ROP between the two groups.

Though not statistically significant but there was a definite decrease in the NEC incidence $(20.5 \%$ vs $11 \%)$ which we attributed to multiple factors as better radiological and surgical support, improved best practices, feeding protocols or use of probiotics and this observation is under analysis in a different study.

Surfactant therapy is an established treatment of RDS. The "best practice" was to give surfactant immediately after birth (prophylactic) rather than use it later (rescue) in preterms, especially in less than 28 weeks of gestations [16]. Since most of these recommendations were based on studies done before antenatal steroid were widely used hence recent studies now advocate a more gentler early stabilization on nCPAP soon after birth, which could avoid intubation in many preterms $[17,18,19]$.

But almost half of these enrolled preterms had treatment failure on nCPAP, hence many clinicians use INSURE technique so as not to deprive the advantages of early surfactant. But this still requires intubation and enough ventilation to prompt inflammation for lung damage to possibly cause chronic lung disease.

Secondly there might be longer periods of ventilation in such infants due to premedication related respiratory depression. In order to avoid intubation but still administer surfactant, clinicians have tried fetal intrauterine surfactant administration using fiberoptic endoscope [20], nebulized surfactant [21], nasopharyngeal installation before delivery of shoulders [22] or using a laryngeal airway mask (LMA) [22].

MIST was initially reported by Kribs et al where they gave surfactant using a fine catheter. [6]. Many German centres are now routinely using feeding tube with Magill forceps to place the tubes while using high flow CPAP system for better surfactant dispersal.
A limitation of this technique was time for acquiring the necessary expertise for the procedure and using a highly flexible orogastric tube which had led Dargaville et al to try a 16 gauge catheter without use of Magill forceps [24]. We have successfully been using a feeding tube, which comes in straight packing and not coiled, hence obviating the need for Magill forceps while the neonate is on bubble nCPAP.

A recognized limitation of our study was it being a single centre study with an inherent design of comparing a retrospective and a prospective cohort. Secondly, in majority of the cases PPHN was diagnosed clinically and confirmed by ECHO only in a few cases. Lastly we had supposed reintubation and MV rates in < $72 \mathrm{hrs}$ at about $50 \%$ with the INSURE group and $30 \%$ in MIST group but on completion of enrolment we found lower reintubation rate of $26.4 \%$ in the INSURE group and $20.3 \%$ in the MIST group.

This was mainly due to higher population of small for gestational age (SGA) preterms in our study compared to other studies. We are not using premedications and there is still an apprehension regarding possible trauma and pain due to the laryngoscope and catheterization while not using sedation in an active neonate but many units in India and abroad, are reluctant to use premedications on those preterms they are planning to extubate immediately after the surfactant.

Despite these limitations our study suggests that the modified MIST technique is well tolerated in preterms for giving surfactant therapy with better clinical efficacy and comparable outcomes than the more invasive INSURE procedure.

It significantly reduced the duration of MV which could reduce the incidence of $B P D$, hence we suggest that it may further be investigated in larger multi-centric trials.

Contributors: RPST: Coordinated patient management and drafting of the initial report; RG \& DY: Supervised management and critically reviewed the manuscript. All authors approved the final version of manuscript.

Funding: Nil, Conflict of interest: Nil Permission from IRB: Yes 


\section{References}

1. Fanaroff AA, Stoll BJ, Wright LL, Carlo WA, Ehrenkranz RA, Stark AR, Bauer CR, Donovan EF, Korones SB, Laptook AR, Lemons JA, Oh W, Papile LA, Shankaran S, Stevenson DK, Tyson JE, Poole WK; NICHD Neonatal Research Network. Trends in neonatal morbidity and mortality for very low birthweight infants. Am J Obstet Gynecol. 2007 Feb; 196(2):147.e1-8.

2. Public Health Foundation of India, All India Institute of Medical Sciences, Save the Children. Zodpey S, Paul VK, editors. State of India's Newborns (SOIN) 2014- A Report. New Delhi: PHFI, AIIMS, SC;2014.

3. Stoll BJ, Hansen NI, Bell EF, Shankaran S, Laptook AR, Walsh MC, Hale EC, Newman NS, Schibler K, Carlo WA, Kennedy KA, Poindexter BB, Finer NN, Ehrenkranz RA, Duara S, Sánchez PJ, O'Shea TM, Goldberg RN, Van Meurs KP, Faix RG, Phelps DL, Frantz ID 3rd, Watterberg KL, Saha S, Das A, Higgins RD; Eunice Kennedy Shriver National Institute of Child Health and Human Development Neonatal Research Network. Neonatal outcomes of extremely preterm infants from the NICHD Neonatal Research Network. Pediatrics. 2010 Sep;126(3):443-56. doi: 10.1542/peds. 2009-2959. Epub 2010 Aug 23.

4. Verder H, Robertson B, Greisen G, Ebbesen F, Albertsen P, Lundstrøm K, Jacobsen T. Surfactant therapy and nasal continuous positive airway pressure for newborns with respiratory distress syndrome. Danish-Swedish Multicentre Study Group. N Engl J Med. 1994 Oct 20;331(16):1051-5.

5. Björklund L, Ingimarsson $\mathrm{J}$, Curstedt $\mathrm{T}$, Johan $\mathrm{J}$, Robertson B, Werner $\mathrm{O}$ et al. Manual ventilation with a few large breaths at birth compromises the therapeutic effect of subsequent surfactant replacement in immature lambs. Pediatric Research. 1997;42(3):348-355. DOI: 10. 1203/00006450-199709000-00016

6. Kribs A, Pillekamp F, Hünseler C, Vierzig A, Roth B. Early administration of surfactant in spontaneous breathing with nCPAP: Feasibility and outcome in extremely premature infants (postmenstrual age d"27 weeks). Paediatr Anaesth. 2007;17:364-9.
7. Silverman WC, Anderson DH. Controlled clinical trial on effects of water mist on obstructive respiratory signs, death rate and necropsy findings among premature infants. Pediatrics 1956; 17: 1-4.

8. Kliegman RM, Walsh MC. Neonatal necrotizing enterocolitis: pathogenesis, classification, and spectrum of illness. Curr Probl Pediatr. 1987 Apr;17(4):213-88.

9. International Committee for the Classification of Retinopathy of Prematurity. The International Classification of Retinopathy of Prematurity revisited. Arch Ophthalmol. 2005 Jul;123(7):991-9.

10. Papile LA, Burstein J, Burstein R, Koffler H. Incidence and evolution of subependymal and intraventricular hemorrhage: a study of infants with birth weights less than 1,500 gm. J Pediatr. 1978 Apr; 92(4):529-34.

11. Jobe AH, Bancalari E. Bronchopulmonary dysplasia. Am J Respir Crit Care Med. 2001 Jun;163 (7): 1723-9.

12. Göpel W, Kribs A, Ziegler A, Laux R, Hoehn T, Wieg C, et al. German Neonatal Network. Avoidance of mechanical ventilation by surfactant treatment of spontaneously breathing preterm infants (AMV): an open-label, randomised, controlled trial. Lancet. 2011;378 (9083):1627-34. DOI: 10.1016/S0140-6736 (11) 60986-0.

13. Kribs A, Härtel C, Kattner E, Vochem M, Küster H, Möller J, et al. Surfactant without intubation in preterm infants with respiratory distress: First multi-center data. Klin Padiatr. 2010; 222:13-7.DOI:10.1055/s-00291241867

14. Kanmaz HG, Erdeve O, Canpolat FE, Mutlu B, Dilmen U. Surfactant Administration via thin catheter during spontaneous breathing: Randomized controlled trial. Pediatrics. 2013;131(2):e502-9. DOI: 10.1542/ peds. 2012-0603.

15. Aguar M, Cernada M, Brugada M, Gimeno A, Gutierrez A, Vento M. Minimally invasive surfactant therapy with a gastric tube is as effective as the intubation, surfactant, and extubation technique in preterm babies. Acta Paediatr. 2014 Jun;103(6):e22933. doi: 10.1111/apa.12611. Epub 2014 Mar 15. 
Original Research Article

16. Yost CC, Soll RF. Early versus delayed selective surfactant treatment for neonatal respiratory distress syndrome. Cochrane Database Syst Rev. 2000;(2): CD001456.

17. SUPPORT Study Group of the Eunice Kennedy Shriver NICHD Neonatal Research Network, Finer NN, Carlo WA, Walsh MC, Rich W, Gantz MG, Laptook AR, Yoder BA, Faix RG, Das A, Poole WK, Donovan EF, Newman NS, Ambalavanan N, Frantz ID 3rd, Buchter S, Sánchez PJ, Kennedy KA, Laroia N, Poindexter BB, Cotten CM, Van Meurs KP, Duara S, Narendran V, Sood BG, O'Shea TM, Bell EF, Bhandari V, Watterberg KL, Higgins RD. Early CPAP versus surfactant in extremely preterm infants. N Engl J Med. 2010 May 27;362(21):1970-9. doi: 10.1056/NEJMoa 0911783. Epub 2010 May 16.

18. Dunn MS, Kaempf J, de Klerk A, de Klerk R, Reilly M, Howard D, Ferrelli K, O'Conor J, Soll RF; Vermont Oxford Network DRM Study Group. Randomized trial comparing 3 approaches to the initial respiratory management of preterm neonates. Pediatrics. 2011 Nov;128(5):e1069-76. doi: 10.1542/peds.2010-3848. Epub 2011 Oct 24.

19. Sandri F, Plavka R, Ancora G, Simeoni U, Stranak Z, Martinelli S, et al. CURPAP Study Group.
Prophylactic or early selective surfactant combined with nCPAP in very preterm infants. Pediatrics. 2010;125

(6):e1402-9. DOI:10.1542/peds.2009-2131

20. Petrikovsky BM, Lysikiewicz A, Markin LB, Slomko Z. In utero surfactant administration to preterm human fetuses using endoscopy. Fetal Diagnosis Therapy. 1995; 10(2): 127-30.

21. Berggren E, Liljedahl M, Winbladh B, et al. Pilot study of nebulized surfactant therapy for neonatal respiratory distress syndrome. Acta Paediatr. 2000;89 (4):460-4.

22. Kattwinkel J, Robinson M, Bloom BT Delmore P, Ferguson JE. Technique for intrapartum administration of surfactant without requirement for an endotracheal tube. J Perinatol. 2004; 24(6):360-365.

23. Attridge JT, Stewart C, Stukenborg GJ, Kattwinkel J. Administration of rescue surfactant by laryngeal mask airway: lessons from a pilot trial. Am J Perinatol. 2013(3); 30:201-6. DOI:10.1055/s-0032-1323592.

24. Dargaville PA, Aiyappan A, Cornelius A, Williams C, De Paoli AG. Preliminary evaluation of a new technique of minimally invasive surfactant therapy. Arch Dis Child Fetal Neonatal Ed. 2011;96(4): F243-8. DOI:10.1136/adc.2010.192518

\section{How to cite this article?}

Tomar RPS, Ghuliani R, Yadav D.Effect of surfactant therapy using an orogastric tube for tracheal catheterization in preterm newborns with respiratory distress. Int. J Pediatr Res.2016;3(10):738-744.doi:10.17511/ijpr.2016.i10.04 